\title{
Interactive comment on "Sea Spray Fluxes from the Southwest Coast of the United Kingdom - Dependence on Wind Speed and Wave Height" by Mingxi Yang et al.
}

Mingxi Yang et al.

miya@pml.ac.uk

Received and published: 11 November 2019

Please see attachment.

Please also note the supplement to this comment:

https://www.atmos-chem-phys-discuss.net/acp-2019-771/acp-2019-771-AC2-

supplement.pdf 